\title{
Styles of Monetary Management ${ }^{*}$
}

\section{TOMMASO PADOA-SCHIOPPA}

\begin{abstract}
Over the years, reflecting a growing consensus on the priority of price stability as the objective of central banks and on market-oriented techniques as the appropriate instruments for monetary control, the focus of the debate has gradually shifted to what can be called the style of monetary policy, or the way in which central banks should formulate and communicate their action to maximize its effectiveness. This paper is concerned with four styles of monetary management, three of which involve a formal, quantified and time-specific precommitment in terms of a single target variable: the exchange rate, the money supply and the rate of inflation. The fourth, which I shall call the "classic" style, relies instead on action, consideration being given to a multiplicity of variables. The experience of the Group of Seven countries in the last 25 years suggests that the styles actually practiced deviated in many instances from those formally announced and that the classic style has been, on the whole, the most widely adopted. Furthermore, a comparison of these countries' inflation performances shows that price stability can be successfully achieved through different styles and that a formal pre-commitment to a single target variable may not be as important in practice as it might appear in theory. Central banks should be aware that trying to influence market expectations by "speaking up before" may be useful but that the best way to win credibility is still through the results they achieve and the determination and consistency they show in their behaviour.
\end{abstract}

Key words: Central banking; Styles of monetary policy

\section{Introduction}

Although the task of providing "sound money" to the economy was attributed to central banks as early as the late 18 th century, the importance of price stability has grown significantly for both central banks and the general public since the high

"Revised version of a keynote address presented at the Seventh International Conference on "Toward More Effective Monetary Policy," sponsored by the Bank of Japan's Institute for Monetary and Economic Studies, October 26-27, 1995. This paper is to be included in the proceedings of the conference to be published from the Macmillan Press. The author expresses his gratitude to Paolo Del Giovane and Valeria Sannucci for assistance and advice in the preparation of this paper. I. Angeloni, L. Guiso. M. Magnani, D. Terlizzese also provided useful comments and suggestions. Responsibility for opinions and errors belongs to the author. 
inflation of the 1970s. Through that experience a new generation became aware of the association of fiat money regimes with inflationary bias in public and private economic behaviour and recognized how much the public good of monetary stability contributes to the material and moral welfare of society. Of the three measures of the value of money - expressed respectively in terms of the goods and services available in the country of the currency (the index of prices), of other currencies (the exchange rate), and of the currency itself in the future (the interest rate) - the first is now generally deemed to be the most important. Price stability today is viewed as a precondition for lasting economic growth: this was not the case 25 years ago, when I joined the central bank of my country.

Over the years, the focus of theoretical discussions concerning monetary policy has shifted from the inflation-unemployment trade-off and the choice of monetary control instruments to the institutional features affecting central banks' activity and the information they disclose about their actions, aims and strategies. Notions such as precommitment, credibility, reputation, independence and accountability, once absent from the vocabulary of central banking, have assumed a key role in discussing central banks and the effectiveness of their action.

In addition to recent experience and theoretical developments, two other factors have tended to foster greater transparency and more active communication. In the first place, technological and financial innovation has led to a world in which market participants are equipped with the same analytical and statistical instruments as central banks and are thus able to monitor the latter's actions in real time; in such conditions central bankers' best course is to complement this "passive" transparency with a more active communication strategy. In the second place, central bankers have had to balance their growing independence vis-à-vis the political sphere with increased accountability for their actions to the government, parliament and the public.

As the debate about monetary policy has gradually shifted away from the priorities and techniques the central bank should adopt, reflecting a growing consensus on the priority to be attributed to price stability and a common understanding of how the monetary mechanism works, the way in which a stabilityoriented monetary policy operating through the money market should formulate and communicate its action in order to maximize its effectiveness has become the central issue. This is what can be called the style of monetary policy, that is to say, the way in which central bankers make their strategy known to the other agents in the economy. I define a "style" as being a course of behaviour which is held with sufficient continuity 
through a variety of circumstances: a later paragraph will explain in what way a style differs from a "rule."

This paper is concerned with styles of monetary management. I shall deal with the subject by first reviewing some basic reference points that central bankers take into account when designing their strategies, i.e., developments in economic theory, information which they can draw and the working of financial markets. I shall then outline and discuss the four styles of monetary management that, in my view, represent the options open to central banks today. Three of them involve a formal, quantified and time-specific precommitment in terms of a single target variable: the exchange rate, the money supply or the rate of inflation itself. The fourth, which I shall call the "classic" style, relies instead on action and openly gives consideration to a multiplicity of variables, thus foregoing both the advantages and the risk of formal precommitments with respect to a single variable. More specific attention will be devoted to inflation targeting, which is perceived today as "the" novelty in monetary management. I will then survey the experience of the G-7 countries with regard to their choice of style and show how at times in the past 25 years central bankers have adhered to a different style from the one they professed to have adopted. I will conclude with some general remarks.

\section{The Theory Kit}

A saying that economic theory is a fundamental reference point for central bankers in the conduct of monetary policy is not such an obvious statement as it might seem. It could not have been made with the same strength 30 or 40 years ago. Nor can it be made today for other policy functions such as banking supervision or the payment system. I can only try to flag the concepts that, on the basis of my own education and professional experience, I regard as the key theoretical reference points for monetary policy.

In a few words, I would say that among the theoretical contributions of the past 60 years there are five which constitute the theory kit that central bankers possess regardless of the depth of their academic background. First, they owe to Keynes the notion of instability, in both real and financial markets, and the recognition of the role of uncertainty and speculation. Second, from Milton Friedman they have reinherited the conviction that, in the long run, money is neutral, and that monetary policy cannot contribute to solving the structural problems of the economy. Third, game theorists 
have clarified that private agents and policymakers interact strategically, anticipating each other's responses, and have thus shifted the picture of the economy from one of mechanistic determinism to one of multiple equilibria in which history matters. Fourth, Robert Lucas has made all policymakers aware that economic agents cannot be assumed to maintain expectations which are systematically falsified. Final, from the neo-Keynesians, they have gained a clearer understanding of the many obstacles to the ideal functioning of markets, stemming from the asymmetric distribution of information, the inertial role of institutions and contracts, and the existence of market power.

In parallel with the debate on the propositions put forward by these various schools of thought, there was a debate on the choice between "rules" and "discretion" in the conduct of monetary policy. And if we push our retrospective observation of economic thinking to embrace the 19th century, this would still hold true, with Keynes and Friedman finding their precursors in Thornton and Ricardo respectively. In the earlier phases of the theoretical debate, "rules" and "discretion" were not necessarily mentioned explicitly. Yet, in most cases the disagreement basically reflected different views on the desirability and effectiveness of discretionary action by policymakers.

Though the issue never seems to be settled, the arguments set forth in support of the two positions have changed considerably over the years. Supporters of the superiority of discretion have abandoned the idea that there exists a trade-off in the long run between inflation and unemployment, while finding it desirable to maintain a capacity to react flexibly to unforeseen shocks. The idea that fine-tuning of the economy is possible has given way to the view that some smoothing action may be helpful in the face of excessive fluctuations. On the other hand, those who argue in favour of rules no longer necessarily base their case exclusively on the fact that monetary policy can exert no more than a temporary influence on real variables and then only after long and variable lags, or on the the claim that market forces alone are able to ensure an efficient allocation of resources. Only a few radical adherents to the rational expectations school would actually claim that unbiased expectations prevent monetary management from being effective even in the short term. The literature based on game theory has shifted the focus of the debate, in that it has shown that rules are often not enforceable, so that a substitute has to be found in "strong" institutions, so that the issue becomes that of defining a strong institution.

Since the proposed rule was the highly simplified one of constant money growth, the alternative "rules versus discretion" tended at first to coincide with the choice 
between non-activism and activism. It later became clear that rules could be complicated and allow for activism by designing a "state-contingent" policy response to shocks. However, I believe that the conflict between activism and non-activism is still present, at a deeper level, once one fully acknowledges the implications of uncertainty. Adding uncertainty to a model does not simply involve adding a stochastic term to its equations. What uncertainty really implies is that there are unforeseeable events that cannot be incorporated in a stochastic rule, no matter how sophisticated it may be. Not only do we not know which, or which combination, of all the possible - known - events will be drawn from the urn; we do not know what the urn actually contains. Recognizing that we do not have perfect knowledge of what is in the urn is, in my opinion, the only way to avoid the dangers inherent in a deterministic view of the branch of social sciences called economics.

In the academic world the various schools have often been drawn up in opposition to each other, almost as if the aim was mutual exclusion. Nevertheless, there have always been leading economists seeking to achieve a synthesis of the different contributions rather than monistically presenting a new discovery as an interpretative passkey and unique prescription for action - John Hicks, Franco Modigliani, Robert Solow, James Tobin are names that spring to mind. Thanks to their efforts, and partly in the light of the events of recent decades, there is now a broad consensus on the long-run neutrality of money, on the influence monetary policy can have on real variables in the short run, on the priority to be assigned to price stability among central banks' objectives, on the limits to the effectiveness of monetary policy in promoting price stability when other economic policies act in the opposite direction, and on the desirability of it not remaining inactive in the face of major economic perturbations.

Apart from the efforts aimed at producing a synthesis within academia, it appears to me that central bankers, precisely because they are faced with practical problems, approach these issues in a non-doctrinaire fashion. The opposition between rules and discretion, activism and non-activism loses some of its force in the face of institutional and practical considerations: once the two extreme hypotheses of deterministic rules and arbitrary action are rejected, experience shows that rules, even when provisos are added, must allow for discretionary action by central banks to cope with the complexity of real life, changes of a structural nature and extraordinary events. A strong central bank is an institution which is in a position to act in a discretionary way.

A final point concerns the limits of the theory kit. The fundamental strands of the 
theoretical debate just recalled refer to a highly stylized economic system. Central banks, however, are faced with the structural characteristics of their particular economy and have to interpret economic doctrine accordingly.

I will not go into this vast subject here, except to stress the importance of the specific features of a country's economic and financial structure for the choice of the style of monetary management. For example, while large and relatively closed economies have considerable freedom of choice and are unlikely to opt for a fixed exchange rate regime, small and open economies are virtually excluded from pursuing an independent monetary policy and may prefer a fixed exchange rate. Similarly, the financial structure - the range of instruments available to firms and households for financing their expenditure, the menu of financial assets available for investing their savings, and the degree of competition prevailing in the financial markets - may be crucial in determining the financial aggregate to be chosen if a strategy based on intermediate targeting is adopted, because the predictability of the relationship between GDP and the various definitions of money or credit depends on the relative stability of the saving, investment and money demand functions. The structural features of both the goods and the financial markets also play a role in the choice between a direct and an indirect targeting system, because the more difficult it is to control inflation (owing, for example, to major budgetary problems or to features of the labour market), the less likely the shift from indirect to direct inflation targeting will be.

\section{The Information Kit}

The other fundamental reference point for central banks is provided by the data on the economy. While the content of the theory kit is rather stable - even more so once the necessary qualifications dictated by the structural features of the economic system are taken into account - the data kit is in continuous turmoil.

Not only does the data kit include a vast assortment of information on all the main economic variables, but it actually provides the picture of a virtual reality just as the configuration of the stars we see at night at a distance of light-years does not actually exist, and in fact never existed, because of the different times it takes light from the various sources to reach the earth. Delays, noise, and other problems in statistical data can affect the choice of targets and indicators central banks use to guide their actions and the temptation to give greater weight to the most easily 
observed variables - which are not necessarily the most meaningful ones - is very strong. Thus, if markets may sometimes find it hard to read the day-to-day behaviour of the central bank, the latter may find it just as difficult to interpret the information they produce.

Consider the case of prices, the crucial variable for a stability-oriented monetary policy. To assess their behaviour accurately, central banks refer to a variety of indices, ranging from consumer prices to more selective ones. ${ }^{1}$ They keep track of the variables - such as the prices of raw materials, labour costs, profits and, in small, open economies, exchange rate movements - that influence consumer prices, albeit to a varying degree and with different lags. Furthermore, they use both aggregate and sectoral information in order to identify potential bottlenecks. ${ }^{2}$

Given the importance of preemptive action, central bankers face the problem of measuring inflation expectations. Opinion surveys, which are a natural and widely used method, suffer from a number of drawbacks: they cannot be updated continuously and the reference time horizon is normally shorter than that required for the conduct of monetary policy. As to market interest rates, it is far from easy to separate out the component associated with inflation expectations. Thanks to the development of indices of implicit volatility based on the prices of options on securities and exchange rates, we now have information on the uncertainty present in the underlying markets and the related risk premia. Nonetheless, the different components of interest rates remain difficult to interpret.

\section{The Market: From Mechanism to Actor}

Equipped with theory and data, central banks used to exercise their judgment and experience to define (sometimes also through discussions and negotiations with the government) their course of action. In doing so, they had in front of them "the

\footnotetext{
'As calculated today in most countries, the consumer price index is open to several criticisms (see "Toward a more accurate measure of the cost of living," interim report to the Senate Finance Committee from the advisory commission set up to study the CPI, September 1995, New York). An example of the difficulty of obtaining an accurate measure of inflation when economic agents' behaviour changes rapidly is provided by the Japanese CPI: the exclusion from the index of purchases at discount stores, which have increased continuously over the past few years, is generally deemed to cause it to underestimate the price deflation currently under way in Japan.

${ }^{2}$ Additional difficulties in forecasting the intensity of potential inflationary or deflationary pressures can arise when factors affecting aggregate demand and supply change swiftly; the rapid asset price inflation and, later on, deflation, that have occurred in the Japanese real estate and equity markets over the past decade are a good example.
} 
economy." The banking system and the money market of course existed and were the first link in the transmission mechanism. But to a large extent they were just a "mechanism," i.e., a system of wheels, belts and shafts that passively - i.e., without producing any unpredictable reactions of its own - passed on the impulses to the rest of the economy.

This is no longer the case. In recent years the financial markets have increasingly become an active interlocutor of the central bank. They have acquired an autonomous and almost irresistible force, which at times works for monetary stability and at others against it. Dialoguing and interacting with the markets, sometimes strategically, is an essential part of central banking today.

The availability on computer screens of a continuous stream of economic, financial and political information concerning a large number of countries, coupled with the rapidity with which operators translate these news flashes into buy-or-sell decisions regarding a vast range of financial products, results, for better and for worse, in highly reactive markets, which end up exercising active control over national economic policies. Since traders have a very short time horizon, privilege marginal news over more important but "slow" events, and look at price changes rather than levels, the prices expressed by markets may temporarily deviate from the levels corresponding to the underlying economic conditions. Over- or under-shooting, noise, protracted misalignments are inherent to a world in which financial transactions are a high multiple of real transactions. And such deviations are not without effect on the economy, even if markets themselves eventually make the necessary correction. It is impossible, with the instruments available, to separate the two aspects (volatility and basic trends) of the behaviour of financial markets.

We may wonder whether the implications for policymaking of the rise of an active financial market have been fully understood yet. In choosing between alternative targets, central bankers cannot ignore, for example, that their ability to control the exchange rate has been severely curtailed by markets' ability to generate massive capital movements. The growth of financial markets may well enhance the effectiveness of monetary policy, if announcements of policy objectives pursued over a definite time horizon do indeed guide expectations: in such a case the market adds power to the process. The same market, however, can exert enormous pressure on exchange rates and the prices of government paper, if policies are perceived as inadequate by reference to the announced objectives: the resulting perturbations not only serve as an indicator of a country's economic health, but also tend to destabilize 
the economy and create difficulties for monetary and economic policy. Markets have become an amplifier, or a damper, of policy impulses, depending on their judgment of both the economic situation and the adequacy of policy actions. Policymakers therefore have to weigh the potential benefits of official and formal precommitments with the costs markets may impose if they take a different view, or if the announced goals are missed.

Central banks also have to reckon with another, more puzzling, aspect of the development of financial markets. The thousands of traders who move enormous sums across the world no longer trust only their intuition, profit motives and market feeling. More and more their trading activity translates theoretical convictions concerning the conduct of macroeconomic policies into price movements, which may end up by validating the original theoretical premises, regardless of whether or not they are sound. The ammunition they can put at the service of a particular policy paradigm forces policymakers to come to terms with economic doctrine in a new and tangible way that has nothing to do with an intellectual contest. Until recently, a theory could affect the economy if policymakers believed it to be correct; today it may suffice that market operators believe it to be correct.

\section{Styles of Monetary Management}

The guidance offered by theory, the continuous movement of markets and the uninterrupted flow of data and news are the elements that central banks consider in conducting monetary policy. Like sailors, who have to take account of charts, the weather and the boat itself, central bankers have to synthesise all these factors in order to set and hold their course. As in navigating, different styles of monetary management are possible. I shall briefly describe the four which cover, in my view, nearly all the methods used by central banks today. The first consists in pegging the exchange rate to another currency. The second and third can be named after the variable adopted as the target: respectively the money supply and the inflation rate. The last style, which I call the "classic" style, differs from the others in that it does not involve monetary policy on its own adopting a formal, quantified and time-specific commitment in terms of a single target variable, but relies more on action and on multiple variables.

Before describing the four styles, I would like to stress that a style is neither a rule nor a fashion. A style is a distinctive manner of behaving which may well not 
include a mechanistic rule or, if a rule is present, provide an interpretation of it that is not necessarily unique. For a line of behaviour to become a "style" it must be implemented with sufficient continuity through a variety of circumstances. How long the period should be for this condition to be satisfied is an open question, of course. I would suggest, however, that a time span falling short of, say, a whole business cycle would prove ineffective in persuading economic agents of the central bank's determination to stick to the declared style. I would also say that the choice of a style should be recognized on the basis of stated intentions and actual behaviour, rather than success in achieving the announced results. Failure to attain a target may be caused by a set of events, of which at least some could be beyond the reach of central bankers. Although deviations from the desired path for the targeted variable are, of course, important in assessing whether the choice was effectively implemented, they are not sufficient to prove that the authorities' commitment was weak. Finally, to be meaningful, the formulation should be such as to bind the behaviour of the central bank: for instance, announcing a target range for the growth of a monetary aggregate equal to or more than twice the lower limit of the band would appear too loose to indicate that targeting had been adopted.

\section{Exchange Rate Pegging}

With the first style of monetary management the exchange rate link can be adopted unilaterally or through a multilateral agreement. The Bretton Woods System and the European Monetary System are the most important examples of multilateral fixed rate arrangements in the second half of the 20th century. Austria and the Netherlands are examples of unilateral fixed rate regimes. The exchange rate style is the one used by the largest number of countries although, when account is taken of the size of each economy, floating rates are far more important than fixed exchange rates.

I shall not refer here to the vast literature on the choice of the optimal exchange rate regime because it is not really relevant for the issues discussed here. Indeed, a large part of this literature is concerned with the question of how relationships between currencies should be organized, and does not deal with the problem of the policy style the $n$-th country or a particular country seen in isolation should follow. For the purpose of deciding whether a country should adopt the exchange rate style, it is sufficient to say that the success of exchange rate pegging in terms of price stability depends crucially on the policy line followed by the country (or group of countries) to 
which the currency is linked. As we all know, however, fixed rate regimes leave this policy line undetermined not only from a functional but, in most cases, also from an institutional point of view, because they do not indicate who will decide the stance of policy. Under Bretton Woods and the EMS, this indeterminateness caused policy conflicts and the eventual breakdown or the virtual suspension of the arrangements. Unilaterally chosen links have functioned well in some cases. In sum, exchange rate pegging ensures price stability only if the policy line is, in the first place, "good" and, in the second, accepted.

\section{Money Supply}

Under the second style of policy, the central bank announces a target for the quantity of money in the coming year and pursues that quantity whatever happens. There are two conditions for this style to be effective: first, the central bank must be able to control the money supply and, second, there must be a sufficiently stable (and statistically observable) link between monetary growth and inflation.

In the second part of the 1970 s many countries abandoned interest or exchange rate objectives and began to target variously defined quantities: domestic credit expansion, central bank money, $\mathrm{M}_{2}$, and so on. The two main reasons given for the switch were the changing nature of the shocks affecting the economy, then originating mainly in the goods market, and the increasing difficulty of setting a target level for interest rates in conditions of high and variable inflation. Behind these reasons there were the inroads made by the monetarist intellectual offensive in the media and the academic and central banking camps. The role of quantity targets diminished in the 1980 s, as rapid financial innovation and deregulation undermined the stability of the relationship between intermediate targets and final variables. In some European countries participation in the ERM led to a reassessment of the importance of monetary targets. The United States, which had adopted new operating procedures under Volcker in 1979 aimed at strengthening the control over monetary aggregates, reverted to a more flexible approach once the stabilization had borne its fruits (and the "debt crisis" of 1982 exploded).

Only one country has elevated the monetary targeting approach into a style: this is Germany, which adopted it in 1975. Over the years the Bundesbank has formulated and presented the rule with varying degrees of stringency and exclusiveness, but it has never abandoned it, or at least never given the outside world the impression of 
allowing it to slip. Notably, in the period following German unification the Bundesbank continued to refer to a target for monetary growth despite the significant overshooting that occurred: the Bundesbank did not change its style and markets did not see the Bundesbank as having become permissive toward inflation.

Monetary targeting is not the only, nor probably the most important, reason for Germany's remarkable record of monetary stability. Other factors have been decisive: the strength of the country's economic structure; the slow pace of financial innovation; and, above all, the fact that, for historical and sociological reasons, the good associated with monetary security has permeated the psychology, behaviour and value systems of all the components of society more deeply in Germany than in any other modern country. In its monetary rule the Bundesbank has found an effective catalyst for these deeply embedded sentiments. In the 1980s and 1990s the German style of monetary management has been exported to a number of countries via exchange rate pegging.

\section{Inflation}

Inflation targeting, which is the "new" style currently receiving considerable attention, is usually described as a regime in which the central bank (a) makes a precommitment to an explicit quantitative inflation target; (b) is free to choose the means to pursue that target; and (c) is accountable for reaching its goal. ${ }^{3}$ While the first characteristic is the essential one, the second and third, though they play a crucial role in this approach, are not specific to it and may also apply to other styles of monetary management.

Inflation targeting is not as novel as it might appear. Central banks have always had a desired, albeit implicit, price performance in mind, even when they resorted to intermediate objectives. Besides, central banks that resort to direct inflation targeting obviously still have to maneuver the variables under their control and to proceed judgmentally, just as they would if they were pursuing an intermediate target. The main difference is that with inflation targeting the announcement takes the form of a public commitment to a quantified objective over a defined time horizon, much as with $\mathrm{M}_{2}$ or $\mathrm{M}_{3}$ in monetary targeting.

The first countries to announce an objective in terms of inflation were New

\footnotetext{
${ }^{3}$ For this definition, see Leiderman and Svensson (1995), Debelle and Fischer (1994) and Goodhart and Vinals (1994). See also Svensson (1995).
} 
Zealand and Canada, between 1989 and 1991. In late 1992 and early 1993 they were followed by the United Kingdom, Sweden and Finland, which had abandoned their exchange rate anchors in the European currency storm. More recently, central banks of other countries - such as France and Spain - have announced an explicit objective for inflation, while retaining a target in terms of a monetary aggregate or the exchange rate. Inflation targeting differs across countries with respect to the reference price index, the length of the time horizon, the adoption of a target range or a single value, the existence of other macroeconomic objectives, and the institutional basis. More specifically, the responsibility attributed to the central bank in each country is quite different. In England the central bank acts as a technical body, which, since it does not even enjoy full instrument independence, is entrusted with the task of signaling the need for a tightening or easing of monetary conditions to the government; in New Zealand and Canada they set the target jointly with the government but are directly responsible for their attainment; and in Sweden and Finland they are responsible for setting the target but the implications of failing to achieve are not clearly defined.

Direct inflation targeting has been used for too short a period and by too few countries to judge its effectiveness on the basis of experience. We can, for the moment, only discuss it a priori.

On theoretical grounds, the adoption of this style is primarily motivated by the desire to provide an anchor for monetary policy and serve as an effective coordination device for price and wage setters and for financial market operators; on a more practical plane, inflation targets are meant to fill the gap left by the abandonment of monetary targets, motivated in turn by empirical problems of instability. While the practical motivation stems from controllability considerations, the theoretical motivation relies on the signaling-catalyst role of inflation targets in influencing expectations and thus reducing the real costs of stabilization. Let me consider these two motivations in turn.

From the narrow viewpoint of controllability, it is very doubtful whether inflation targeting can perform better than monetary targeting. Since central banks do not exert fuller or more direct control over inflation than over $M_{2}$ or $M_{3}$, the former style of monetary management, by definition, does not overcome the difficulties that led to the abandonment of the latter. Indeed, by shifting from monetary to inflation targeting, the problems of controllability posed by the unreliability of the link between central bank instruments and monetary aggregates are not really avoided, if one still 
believes that such aggregates are crucial to the control of inflation. And a similar argument applies to other intermediate variables, such as interest rates, the exchange rate, and total credit. Moreover, such old problems are aggravated by new ones, arising from the segment of the transmission mechanism that goes from intermediate variables to prices. This is so because factors such as labour costs, the exchange rate and raw material prices undoubtedly influence prices and yet are partly outside the reach of monetary policy. And other factors, such as the state of the public finances, may also affect interest rates and the exchange rate and end up by being reflected in prices.

This leaves the signaling-catalyst role of inflation targeting. If inflation targeting proved more effective than - say - monetary targeting in influencing expectations and hence the pricing behaviour of economic agents, it could be hoped that effectiveness would be regained through a shortcut. But the problem here is: what will bring inflation on track if the signaling-catalyst process does not work as planned, that is to say if it does not prove powerful enough to overcome the influence on price performance exercised by some of the other factors I mentioned above? This brings us back to the controllability problem. The introduction of escape clauses when announcing the target could alleviate the problem; but there are so many possible shocks that the addition of a string of provisos would result in the announcement of the target losing most of its signaling effect.

There is some circularity in the process. The solution to the controllability issue depends crucially on the hypothesis that inflation targeting, thanks to its signalingcatalyst power, does indeed enhance the role of expectations in the transmission of monetary policy impulses in comparison with alternative approaches. At the same time, this signaling-catalyst power is bound to depend on the credibility of the announcement, that is to say on the confidence that the central bank really is able to control inflation.

In view of these considerations, it has been suggested that to gain credibility in a relatively short time span, a more controllable target may be preferable, provided enough people pay attention to it, while a less controllable and more visible target may be adopted where the central bank has a solid reputation and can hence exploit the role of expectations more powerfully, without suffering a significant loss of credibility if the target is not achieved. ${ }^{4}$ It is worth noting, however, that the Bundesbank, which is

\footnotetext{
${ }^{4}$ See Cukierman (1995).
} 
usually reckoned to have the highest reputation, remains faithful to indirect targeting. This is partly because financial innovation has not yet caused insurmountable measurement and control problems in Germany, but it also owes much to the considerable effort systematically deployed by the Bundesbank to explain its actions, thus increasing the number of people who pay attention to the results obtained even though the intermediate objective is not particularly visible.

It is often said that the greater the distance separating monetary policy from its objective under inflation targeting, the more transparency is required on the part of the central bank for its action to be effective. Both markets and the public must be given a detailed explanation of the factors and reasoning that guide its decisions in the short term. The inflation reports published by the Bank of England and the Swedish central bank are a response to this need. In practice, however, it is just as important for the central bank to explain policy with the other styles of monetary management, so that this distinction between direct and indirect targeting is not really valid.

Time will tell whether inflation targeting will become firmly established or wither away like other styles, such as that based on a target for nominal income, which I have not mentioned here. In several respects, inflation targeting does not appear to be dramatically innovative in comparison with intermediate targeting: it is unlikely to outperform the latter in terms of controllability and effectiveness in building a reputation; nor does it necessarily ensure more transparency and accountability. It undoubtedly has the merit of focusing attention on what central banks prize most, monetary stability. However, it is precisely this merit that also constitutes its most serious drawback, because it obliges the monetary authorities to make a formal commitment with respect to an economic variable that is beyond its full and direct control, especially in the short time horizon that is used for judging monetary policy actions. Inflation targeting may lead a central bank to gamble its credibility, and hence the effectiveness of its action, for want of caution or because of an excess of ambition. It is as if the police were to announce in figures the reduction in the rate of crime it plans to achieve in the coming year, instead of striving to reduce it "as much as possible."

\section{The "Classic Style"}

With the fourth style monetary policy relies on actions more than on precommitments, although all central banks now "speak up" their aims. Central banks 
using this style refer to the whole body of theoretical and empirical knowledge about the functioning of the economic system. In view of the complexity of functional relationships between economic variables, central banks know that the significance of any single indicator may vary with the circumstances. In a world of uncertainty, any commitment taking the form of a "simple" announcement may prove too costly in terms of credibility. These central banks do not make formal, quantified and timespecific commitments with regard to a single variable, either intermediate or final.

This style can be called "classic" for two reasons. First, because it is the one that has been in use longest in the majority of leading countries, including Japan and the United States. Second, because it is the one that makes the most complete use of the information available to central banks and takes the greatest account of the aspects of economic theory that bear on central banking. As in the case of supervision constructive ambiguity allows responsible behaviour on the part of individual banks to be combined with the possibility for the authorities to prevent contagions that may have disruptive effects, in monetary management some degree of imprecision in stating central banks' intentions leads to an improved trade-off between credibility and smoothing action.

The fundamental difference between the classic style and the three others is the lack of a formal and quantified precommitment by the central bank, so it is with reference to this that we have to discuss its validity.

On theoretical grounds, a policy based on an announced objective has the key advantage of offering a reference point for expectations. However, when such announcements are made in a formalized and quantified manner, there may be a down side if uncertainty or unforeseeable factors make it impossible to stick to the strategy that has been announced. In a continuously changing world, such a precommitment can prove very costly, especially if the process of establishing credibility is hampered by inflation-prone behaviour on the part of other key economic agents (such as the government, employers and organized labour) and if markets are quick to punish and slow to forget. On the other hand, the potential advantages of a policy based on formal precommitments may be negligible if the central bank already enjoys a strong position.

A policy style that foregoes the technique of sound-bite announcements may appear unattractive in a modern information society, in which central banks and their actions receive daily media coverage and markets are constantly seeking new information and interpretations, with the corollary of an exasperated need to simplify 
and schematize. The classic style is not simple to explain, summarize or interpret; it calls for patience and is ill-suited to the "skimming" typical of newspaper readers and foreign exchange traders. On the other hand, it has the advantage of greater interpretative power and openness to new contributions, a broader statistical basis, and a long and illustrious tradition. The other styles are perhaps more useful for judging monetary policy than for implementing it.

The advocates of inflation targeting and of other approaches based on precommitments tend to use a very simplistic version of their approach when they intervene in the media to comment on central bank actions, but they are much more careful in their academic work, where they surround the proposed method with so many qualifications that much of the merit of simplicity and easy signaling they praised in the media is actually lost.

It would be unfair to extol the virtues of the classic style without recognizing the influence that the various schools of economic thought have had on its evolution. Twenty-five years ago adherence to the classic style implied central banks hardly ever talking on public occasions; communication with the outside world was restricted to the publication of official reports coming out perhaps once a year; "silence" ("le silence de la monnaie" in J. Rueff's words) was the key to the optimal behaviour of those entrusted with the management of money. Attention was devoted to a fairly limited amount of financial data basically consisting in a long-term interest rate and the exchange rate. The desire to exploit a Phillips curve trade-off played a large role in the decision-making process.

Since then, the classic style has evolved considerably, learning from and adapting to theoretical developments, the growth of the financial markets and the experience gained using the other styles. Compared with the time I moved from graduate school to the central bank, the classic style now assigns clearer priority to the objective of countering inflation, pays more attention to monetary aggregates, attributes greater importance to the exchange of signals with the market, gives more weight to the medium term than the short term, seeks to ensure consistency in its policies, and discloses more detailed information on its decisions, interpretations and intentions.

All these are positive features that the classic style partly owes to schools that have opposed it, although it should be noted that in the transition from theory to practice such schools have lost some of their inflexibility and rigidity. I still see a dividing line, however, between monetary policy on its own adopting and not adopting a style based on what I have called a formal, quantified and time-specific commitment 
in terms of a single target variable.

\section{The Choice of a Style: The Past 25 Years}

With the qualifications outlined above, we can try to review where countries stand - or have stood - on the style of monetary management. If I were to take the 175 observations of the monetary policy style used by individual Group of Seven countries in each of the 25 years that I have worked in the Bank of Italy and weight them by the size of their economies, the resulting indicator would show the classic style to be way out in front. Let me explain this conclusion by briefly reviewing the record of each of the four styles. I will begin by illustrating a sketchy picture of targets for the exchange rate or for domestic variables in the G-7 countries since 1970 (Table 1). ${ }^{5}$ I will then argue that the style actually practiced in many instances deviated from formally stated intentions and conclude that the classic style has been the predominant one (Table 2).

Inflation targeting cannot be judged yet because its appearance in the list of styles is too recent. I will simply observe that, leaving aside the somewhat extreme case of New Zealand, most of the countries adopting it view their inflation "target" much in the same way as many other countries - including my own - view a desired performance for prices over the medium term as a reference point guiding individual and collective behaviour. It may be established on the basis of a scenario drawn up by the government as part of its general economic policy functions, or by the government and the central bank. With this benchmark in mind, the central bank explains its conduct of monetary policy in its regular publications and in hearings before Parliament. ${ }^{6}$ This reference to inflation does not have the structured procedure, or the binding character, or - for the moment - the protracted period of implementation that would make it a style. Even in those countries (such as Finland and Sweden) in which the target is set by the central bank alone, the announcement does not (or perhaps does not yet) have the strong features that make a style.

\footnotetext{
${ }^{5}$ An interesting overview of the experience in 100 countries has been provided by Cottarelli and Giannini (1995).

${ }^{6}$ The way inflation targeting is actually implemented in the countries adopting it is described in Del Giovane and Grande (1995) and in Leiderman and Svensson (1995).
} 
Table 1

Targets for the Exchange Rate and for Domestic Variables:

The G-7 Countries in 1970-94

\begin{tabular}{lcccc}
\hline \hline & \multicolumn{2}{c}{ Exchange rate } & \multicolumn{2}{c}{ Announced targets for: } \\
& arrangements & Money supply & Inflation \\
\hline USA & BW & $1970-71$ & $1975-94$ & - \\
Japan & BW & $1970-71$ & - & - \\
Germany & ERM & $1979-94$ & $1975-94$ & - \\
France & BW & $1970-71$ & $1977-94$ & - \\
& S & $1972-73$ & & \\
& ERM & $1979-94$ & & $1993-94$ \\
United & BW & $1970-71$ & $1976-92$ & $-{ }^{*}$ \\
Kingdom & ERM & $1990-92$ & & \\
Italy & BW & $1970-71$ & $1985-94$ & $1991-94$ \\
& S & 1972 & & \\
& ERM & $1979-92$ & & \\
Canada & - & & $1976-82$ & \\
\hline \hline
\end{tabular}

* Total domestic credit was targeted from 1974 onward; by the middle of the 1980s the role played by this aggregate had been openly deemphasized.

BW: Bretton Woods system.

S: "Snake."

ERM: Exchange Rate Mechanism of the EMS.

More extensive comments are required for the exchange rate and monetary targeting experiences, which are longer and more diversified. As concerns the exchange rate, I shall consider the cases during the past 25 years in which the external value of a currency played the role of a nominal anchor. Among the G-7 countries, this occurred in the years preceding the collapse of the Bretton Woods system and, more importantly, under the European currency arrangements. The participation of France, the United Kingdom and Italy in the "Snake" was discontinuous and not very significant compared with their participation in the Exchange Rate Mechanism of the EMS: on the part of France during the whole period from 1979 to 1995, of Italy from 1979 to 1992, and of the United Kingdom for the two years in which it took part. 
Table 2

Styles of Monetary Management Actually Followed:

The G-7 Countries in 1970-94

\begin{tabular}{|c|c|c|c|c|}
\hline & $\begin{array}{c}\text { Exchange rate } \\
\text { pegging }\end{array}$ & Money supply & Inflation & Classic style \\
\hline USA & 一 & $1979-84$ & - & $\begin{array}{l}1970-78 \\
1985-94\end{array}$ \\
\hline number of years & & 6 & & 19 \\
\hline $\begin{array}{l}\text { Japan } \\
\quad \text { number of years }\end{array}$ & $\begin{array}{c}1970-71 \\
2\end{array}$ & 一 & - & $\begin{array}{c}1972-94 \\
23\end{array}$ \\
\hline $\begin{array}{l}\text { Germany } \\
\quad \text { number of years }\end{array}$ & 一 & $\begin{array}{c}1975-94 \\
20\end{array}$ & - & $\begin{array}{c}1970-74 \\
5\end{array}$ \\
\hline France & $\begin{array}{l}1970-71 \\
1979-94\end{array}$ & - & - & $1972-78$ \\
\hline number of years & 18 & & & 7 \\
\hline United Kingdom & $\begin{array}{l}1970-71 \\
1990-92\end{array}$ & $1980-83$ & 1993-94 & $\begin{array}{l}1972-79 \\
1984-89\end{array}$ \\
\hline number of years & 5 & 4 & 2 & 14 \\
\hline Italy & $\begin{array}{l}1970-71 \\
1979-92\end{array}$ & - & - & $\begin{array}{l}1972-78 \\
1993-94\end{array}$ \\
\hline number of years & 16 & & & 9 \\
\hline $\begin{array}{l}\text { Canada } \\
\quad \text { number of years }\end{array}$ & 一 & - & $\begin{array}{c}1991-94 \\
4\end{array}$ & $\begin{array}{c}1970-90 \\
21\end{array}$ \\
\hline Total number of years & 41 & 30 & 6 & 98 \\
\hline
\end{tabular}

Notwithstanding various realignments for France and, even more, for Italy, and in spite of the fact that Italy and the United Kingdom had a 6 percent fluctuation band, it is fair to say that adherence to the ERM in fact set the style of monetary management for the participating countries and played a key role in their achieving disinflation.

Of course the choices of the G-7 central banks were also guided by exchange rate considerations in a number of other cases. For instance, they were crucial in explaining the policy adopted by the Federal Reserve in 1985-86, when a depreciation of the US dollar was actively pursued. And the Bank of England appears to have had 
similar concerns in 1987-88, when the appreciation of the pound was deemed to be excessive. But these instances in no way fit a meaningful definition of the exchange rate style. Even the Canadian experience of de facto pegging of the exchange rate to the U.S. dollar over the 1978-83 period is a dubious application of this style since the decision to abandon the exchange rate pegging policy was linked to the desire to alleviate the effects of the cyclical downturn.

As to monetary targeting, it seems, prima facie, to have been widely used in the past 20 years, replacing the "adjustable peg" regime that issued from the Bretton Woods Conference. If we leave aside Japan - which formulated forecasts, rather than targets, for money supply - all the other G-7 countries announced growth targets for one or more aggregates at some stage between the mid-1970s and the early 1990 s. $^{7}$ Yet, if we take a closer look at each country's experience, we find that Germany is the only clear-cut example of a monetary targeting style having been adopted. Let me explain this point.

Considering the United States and the United Kingdom first, they introduced formal targets in 1975 and 1976 respectively, but pursued them in a relatively loose way until the end of the 1970s. In the United States, the weakness of the commitment is shown by the recourse made to base drift and by the way interest rates were maneuvered. In the case of the United Kingdom, recourse was made to administrative controls (the "corset"). Money supply targeting was made more binding in 1979, after the second oil shock, when the Federal Reserve introduced new operating procedures and the Thatcher government adopted a Medium Term Financial Strategy in the United Kingdom. Monetary targeting was, however, de facto attenuated three or four years later in both countries. In the United States, the first indications of a style change can be seen in the new operating procedures that were introduced in the fall of 1982; the analysis presented by Benjamin Friedman (1995) in this conference suggests that the Fed's commitment to money supply targeting was significantly reduced after 1984. Partly as a result of the difficulties caused by financial innovation, targets were regularly exceeded in both the United States and the United Kingdom over the 1979-82 period. Since 1982 (in the United States) and 1984 (in the United Kingdom) a target range, which in most cases was greater than or equal to 100 percent of the lower limit, was announced. In the United States, over the whole period announcements referred to more than one aggregate; indeed, at times four measures of

\footnotetext{
${ }^{7}$ Useful surveys of monetary targeting experience can be found in Bernanke and Mishkin (1992), Monticelli and Strauss-Kahn (1992), Passacantando (1995) and BIS (1991).
} 
money supply were targeted, as well as a credit aggregate. In February 1993, the Chairman of the Fed announced that less weight was being given to money supply targeting. To sum up, if I had to single out the periods in which money supply targeting was viewed as "the" style of monetary management in the United States and the United Kingdom, I would choose, respectively, 1979-82 (or at most 1984) and 1980-83.

In Canada, money supply growth targets were announced at irregular intervals between 1976 and 1982; for most of the period, the Canadian dollar was de facto pegged to the U.S. dollar; in 1981-82 the target range cannot be viewed as having been binding. As to France and Italy, targeting of a credit aggregate or of a money supply measure coexisted for quite a long time first with the application of credit ceilings, then with the adoption of the exchange rate as a nominal anchor, and has been played down even more over the past couple of years.

Germany is thus left as the only country that has consistently followed monetary targeting for a long period, well beyond the minimum required for it to be considered a style. The mechanism was revised a number of times, with central bank money being replaced by $\mathrm{M}_{3}$ and single value targets by ranges of two or three percentage points. But throughout the period an announcement was made, toward the end of the year, of the monetary growth set as the (only) objective for the coming year.

Targets were overshot nine times and undershot twice in the 20 year period. Persistent overshooting occurred in 1975-78 and in 1986-88, but the fact that this did not undermine the Bundesbank's credibility was due to its reputation being underpinned by the excellent results achieved in terms of the stability of the deutsche mark, both in the past 20 years and in the earlier postwar period.

This brief overview suggests that even when a country claimed to have adopted (monetary or exchange rate) targeting, there is scant evidence of the central bank behaving in accordance with the chosen approach over a long enough period or strictly enough to justify using the word "style." The classic style prevails.

Beyond the stated objectives that characterize the style, however, we have to look at the performance in terms of price stability, even though very few countries targeted inflation as such. Between 1955 and 1994 the annual increase in German consumer prices averaged 3.2 percent; it was below 3 percent in no less than 21 of these 40 years and above 6 percent in only four years; it never exceeded 7 percent. In Japan, where the classic style has been consistently followed, the results were comparable to those achieved by Germany: Japanese inflation has averaged 3.6 percent since fixed 
exchange rates were abandoned in 1974 and was 4.6 percent over the 40 year period; it was below 3 percent in fifteen of the 40 years and above 7 percent in eight years. Over the same 40 year period the average annual rate of inflation was 4.4 percent in the United States, 6 percent in France, 6.8 percent in the United Kingdom, and 7.7 percent in Italy. It was less than 3 percent in 14 years in the United States, 11 in France, eight in the United Kingdom, and nine in Italy; it exceeded 7 percent six times in the United States, 13 times in France and the United Kingdom, and 14 times in Italy.

If we focus our attention on the two most successful and relatively unambiguous cases - i.e., Germany's experience with monetary targeting and Japan's application of the classic style - we establish some points. First, both experiences show that credibility and flexibility are not necessarily incompatible; as the former is consolidated, the conflict with the latter diminishes and gives way to complementarity. German flexibility is shown not only by over- and under-shootings but also by indications that counter-cyclical considerations were a factor in policy decisions. Second, the German case suggests that the causal link between monetary targeting and price stability probably acts in both directions; the former can be seen as an "expression" of the latter, not just one of its determinants. Third, a long time seems to be needed for attitudes oriented toward price stability to become firmly rooted in society and for them to be embodied in the expectations held by the markets, which are said to have a short sight but a long memory. Finally, the performances of Japan and Germany indicate that price stability can be successfully achieved through different styles and, more specifically, that precommitment may not be as important in practice as it might appear in theory. As a result, more than to the choice of the style in itself, attention should be paid to the process aimed at establishing a solid record in terms of strength, technical competence, time consistency, and good anti-inflationary performance. In turn, experience suggests that all these elements are more effectively gained and defended if adequate energies are devoted by the central bank to explaining the hypotheses underlying the formulation of its strategy, the uncertainties connected with them and the difficulties encountered in pursuing its goals. Once transparency is ensured, flexibility can enhance reputation.

\section{Conclusions}

In the debate about monetary policy a consensus exists today on the priority to be 
attributed to price stability and on the need to operate through markets. The attention once paid to the definition of goals and the choice of techniques is now addressed to what I have called the "style" of monetary management.

A retrospective view of the past 25 years highlights the evolution undergone by the central banks' concept of the best way to implement their commitment to fighting inflation. If we leave aside the choice of an exchange rate regime, which only indirectly implies the choice of a style, we are left with the overwhelming impression that both the various styles based on precommitment and the one I have referred to as the classic style have been subject to a wide variety of interpretations. The former have profoundly influenced the latter, which however appears to have been the predominant choice.

The fact that precommitment does not appear to have been widely used does not imply that central banks are uncommitted and opaque. Rather, it suggests that commitment should not be identified with a formal, quantified and time-specific precommitment on the part of the central bank in terms of a single target variable and that transparency should not be reduced to announcements. Central banks adopting the classic style try to eschew both the gambles and the monistic bias of some recent strands of theory, while incorporating the useful elements that can be distilled from them and from experiences inspired by them. They surely "speak up before" and try to influence market expectations, but they do so knowing that they win their credibility with the results they achieve and the determination and consistency they show in their behaviour. They are by no means inherently less transparent and accountable than central banks adopting inflation targeting.

In the pursuit of sound money the central bank can and does play a crucial role not only through its operations but also, and perhaps more, by determining the attitude of society towards price stability. For if the central bank fights its battle against inflation on the front line, the home front is no less important: in the end the whole country is responsible for its own rate of inflation. The ultimate secret of the monetary stability that Germany and Japan have enjoyed for more than forty years, and which they still enjoy today, is the extraordinary strength of the home front. This strength, in turn, owes much to the efforts of a central bank constantly seeking to inform, educate and clarify; such efforts are an integral part of the defense of the currency's value.

\section{Tommaso Padoa-Schioppa: Deputy Director General, Bank of Italy}




\section{References}

Bank for International Settlements, The Orientation of Monetary Policy and the Monetary Policy Decision-making Process, Basle, April 1991.

Bernanke, B. and F. Mishkin, "Central Bank Behaviour and the Strategy of Monetary Policy: Observations from Six Industrialized Countries," NBER Working Paper No.4082, May 1992.

Cottarelli, C. and C. Giannini, "Credibility without Rules? Monetary Frameworks in the Post Bretton-Woods Era," Paper prepared for the Eleventh World Congress of the International Economic Association, Tunis, December 18-22, 1995.

Cukierman, A., "Towards a Systematic Comparison between Inflation Targets and Monetary Targets," in Leiderman and Svensson, eds., Inflation Targets, CEPR, 1995.

Debelle, G. and S. Fischer, "How Independent Should a Central Bank Be?," in J.C. Fuhrer, ed., Goals, Guidelines and Constraints Facing Monetary Policymakers, Federal Reserve Bank of Boston, 1994.

Del Giovane, P. and G. Grande, "Targeting dell'inflazione: principali aspetti teorici e di attuazione," mimeo, Banca d'Italia, December 1995

Friedman, Benjamin, "The Rise and Fall of Money Growth Targets as Guidelines for U.S. Monetary Policy," in Kuroda, ed., Towards More Effective Monetary Policy, London: Macmillan, 1996 (forthcoming).

Goodhart, C.A.E. and J. Vinals, "Strategy and Tactics of Monetary Policy: Examples from Europe and the Antipodes," in J. C. Fuhrer, ed., Goals, Guidelines and Constraints Facing Monetary Policymakers, Federal Reserve Bank of Boston, 1994.

Leiderman, L., and L. E. O. Svensson, eds., Inflation Targets, CEPR, 1995.

Monticelli, C. and M.-O. Strauss-Kahn, "Broad Monetary Aggregates and National Money Demand in Europe," in Economie et Sociétés, Série Economie Monétaire, M.O., 9, September-October 1992.

Passacantando, F., "Building an Institutional Framework for Monetary Stability: The Case of Italy (1979-1994)," Quarterly Review, Banca Nazionale del Lavoro, March 1996.

Svensson, L., 'Optimal Inflation Targets, 'Conservative Central Banks' and Linear Inflation Contracts," Paper prepared for the European Summer Symposium in Macroeconomics hosted by the Bank of Italy, Perugia, June 28 - July 2, 1995. 